\title{
Aerosol Parameter Estimation Method Utilizing Solar Direct and Diffuse Irradiance Measuring Instrument without Sun Tracking Mechanics
}

\author{
Kohei Arai ${ }^{1}$ \\ 1 Graduate School of Science and Engineering \\ Saga University \\ Saga City, Japan
}

\begin{abstract}
Estimation method of aerosol parameter by means of solar direct and diffuse irradiance measurements with the proposed instrument of fiber-ball radiometer without sun tracking mechanics is proposed. Sky-radiometer and aureolemeter is well known instrument which allows measurements of solar direct and diffuse irradiance for estimation of aerosol parameter. The proposed fiber-ball radiometer also allows solar direct and diffuse irradiance measurements and is comparatively light as well as is composed without any mechanics so that it is portable and is enable to bring anywhere you want including test sites for field campaigns. Meanwhile, it is not always that the fiber-ball instrument points to the sun due to the error of the sun ephemeris calculations as well as sun track do not match to the actual one. Influence due to pointing error on aerosol parameter estimation error is clarified. Possible maximum pointing error may cause some error on aerosol parameter estimation. Experimental results show that $\mathbf{0 . 4 3 \%}, \mathbf{4 2 . 2 3 \%}, \mathbf{2 . 1 2} \%$ root mean square errors are suspected for real and imaginary part of refractive index and Junge parameter as of 1.747, 0.0056 and 3.0 of typical case of atmosphere.
\end{abstract}

Keywords-Aerosol; Atmospheric optical depth; Solar irradiance; Solar direct; Solar diffuse; Aereole; Junge parameter; Size distribution; Real and imaginary parts of refractive index

\section{INTRODUCTION}

The largest uncertainty in estimation of the effects of atmospheric aerosols on climate systems is from uncertainties in the determination of their microphysical properties, including the aerosol complex index of refraction that in turn determines their optical properties. The methods, which allow estimation of refractive indices, have being proposed so far [1]-[3].

Most of the methods use ground based direct, diffuse and aureole measurement data such as AERONET [4] and SKYNET [5]. The methodology for estimation of a complete set of vertically resolved aerosol size distribution and refractive index data, yielding the vertical distribution of aerosol optical properties required for the determination of aerosol-induced radiative flux changes is proposed [6].

The method based on the optical constants determined from the radiative transfer models of the atmosphere is also proposed [7]. Laboratory based refractive indices estimation methods with spectral extinction measurements are proposed
[8], [9]. All these existing methods are based on radiance from the sun and the atmosphere.

Through atmospheric optical depth measurements with a variety of relatively transparent wavelength, it is possible to estimate size distribution, molecule scattering, gaseous transmission, ozone and water vapor absorptions, etc. so that refractive index might be estimated [10]-[14]. In order to assess the estimation accuracy of refractive index with the proposed method, sensitivity analysis is conducted with a variety of parameters of the atmosphere. In particular, observation angle dependency is critical for atmospheric optical depth measurements. Therefore, it is conducted to assess influences due to observation angle on estimation accuracies of refractive index and size distribution. Similar researches are conducted and well reported [15]-[27].

Most of measuring instruments which allows solar direct and diffuse irradiance measurements has sun tracking mechanics of which some malfunctions may occur sometime and it requires not so short time for collecting data of solar direct and diffuse irradiance. In order to overcome such problems, a new type of spectral radiometer without sun tracking mechanics is proposed here.

The next section describes the proposed system followed by experiment. The experiments are intended to show the sensitivity of solar direct and diffuse pointing angle on the aerosol parameter estimations. Then concluding remarks are described with some discussions.

\section{PROPOSED METHOD}

\section{A. Conventional Method for Aerosol Parameter Estimation}

Conventional method for aerosol parameter estimation is based on radiative transfer equation with measured solar direct and diffuse irradiance from the ground. The radiative transfer equation represents relation between solar direct and diffuse irradiance as well as aerosol parameters, refractive index and size distribution. Therefore, it is important to measure the solar direct and diffuse irradiance precisely. It usually requires solar tracking capability. Sun ephemeris can be calculated with the location and time information. Once the sun is acquired, the sun is tracked automatically. One of the solar direct and diffuse irradiance measuring instruments is shown in Fig.1. This is called as SkyRadiometer POM-01 
manufactured by Prede Co. Ltd in Japan. Top left in Fig.1, there are two optics. One is for optical entrance of the radiometer while the other one is for sun tracker. Solar direct, Aureole, Diffuse irradiance can be measured with the main radiometer through the optical entrance. It covers ultra violet to near infrared wavelength. 315, 400, 500, 675, 870, 940 and $1020 \mathrm{~nm}$ is center wavelength of the radiometer. $315 \mathrm{~nm}$ is for ozone absorption band while $940 \mathrm{~nm}$ is for water vapor absorption band. Other five bands are transparent bands. In other word, atmospheric optical depth for these five bands is very thin. Using these two band data, column ozone and column water vapor is estimated. Major specification of the POM-01 is shown in Table 1 .

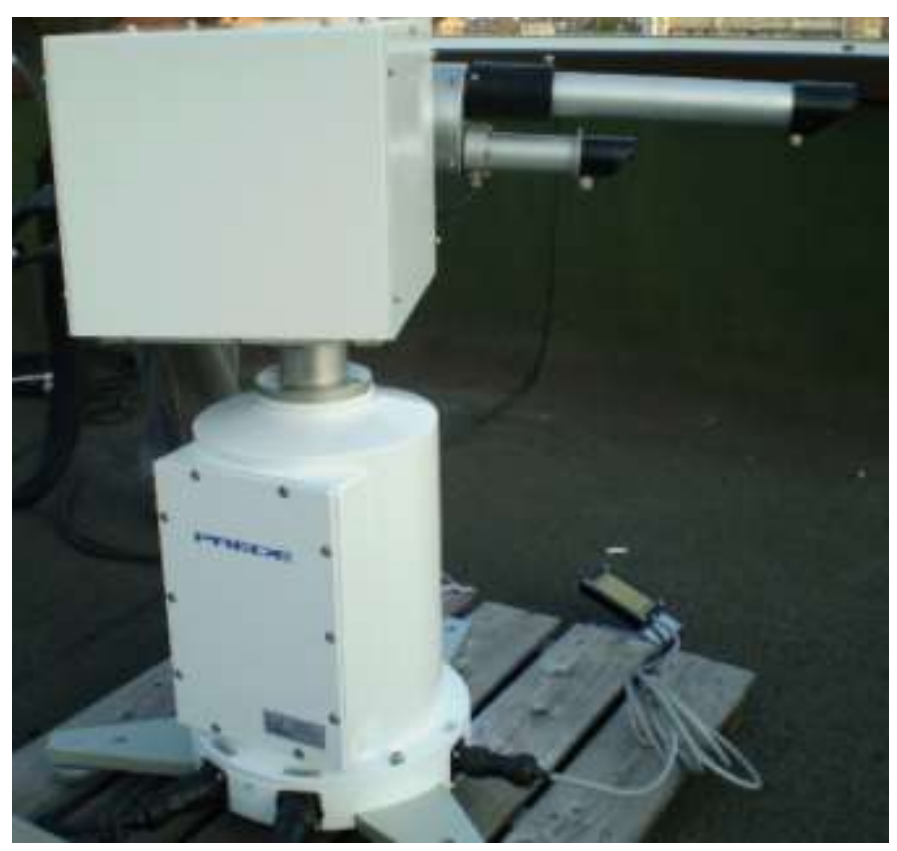

Fig. 1. Outlook of POM-01

TABLE I. MAJOR SPECIFICATION OF POM-01

\begin{tabular}{|l|l|}
\hline Field_of_view & $0.5^{\circ}$ \\
\hline Minimum_scattering_angle & $3^{\circ}$ \\
\hline Wavelength & $315,400,500,675,870,940,1020 \mathrm{~nm}$ \\
\hline Band_Selection & Filter_Wheel \\
\hline Detector & Silicon_Photo_Diode \\
\hline Measurable_Range & $2.5 \mathrm{~mA}, 250 \mu \mathrm{A}, 25 \mu \mathrm{A}, 250 \mathrm{nA}, 25 \mathrm{nA}, 2.5 \mathrm{nA}$ \\
\hline Drive_System & Pulse_Motor \\
\hline Measuring_Interval & Air-mass \\
\hline Scan_Direction & Horizontal/Vertical_Directions \\
\hline Measurable_Scattering_Angle & 50 \\
\hline
\end{tabular}

Response time is not so fast. It requires not so short time for measurement of solar direct and 50 points of diffuse irradiance. During the measurement, the atmosphere may change. Due to the fact that the sun tracking needs mechanics. Therefore, undesirable malfunction occurs sometime. The proposed system is developed to overcome such that problems. Namely, solar direct and diffuse irradiance measuring instrument without sun tracking mechanics is proposed here.

\section{B. Proposed Method for Aerosol Parameter Estimation}

The proposed method for aerosol parameter estimation is ased on radiative transfer equation with measured solar direct and diffuse irradiance which is acquired by the measuring instrument of the irradiance without sun tracker. Fundamental spectral-radiometer is based on the existing commercially available spectral-radiometer of MS-720 manufactured by Eiko Co. Ltd. Outlook and major specification is shown in Fig. 2 and Table 2, respectively. MS-720 is the portable type of spectral-radiometer of which the wavelength coverage from ultra-violet to near infrared $(350-1050 \mathrm{~nm})$ with the Zeiss grating element and silicon photo diode array of 256 channels. Spectral radiant flux can be measured with this MS-720. Wavelength interval is $3.3 \mathrm{~nm}$ while $\pm 5 \%$ of detector temperature correction can be done with this MS-720. Aperture angle (180, 90, 10 degrees) can be changed with attachment of the optical entrance.

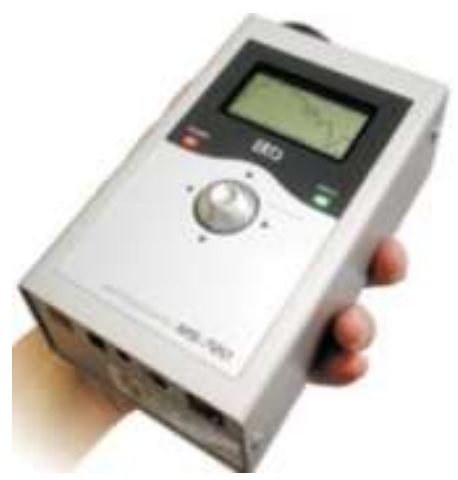

Fig. 2. Outlook of MS-720

TABLE II. MAJOR SPECIFICATION OF MS-720

\begin{tabular}{|l|l|}
\hline Wavelength_Coverage & $350 \sim 1,050 \mathrm{~nm}$ \\
\hline Wavelength_Interval & $3.3 \mathrm{~nm}$ \\
\hline Wavelength_Resolution & $10 \mathrm{~nm}$ \\
\hline Wavelength_Accuracy & $<0.3 \mathrm{~nm}$ \\
\hline Full_Aparture & $180^{\circ}$ \\
\hline StrayLight & $<0.15 \%$ \\
\hline Temperature_Dependency & $\pm 5 \%$ \\
\hline Output_Unit & $\mathrm{W} / \mathrm{m} 2 / \mu \mathrm{m} \_$or_ $\mu \mathrm{mol} / \mathrm{m} 2 / \mathrm{s} / \mu \mathrm{m}$ \\
\hline Measuring_Interval & $0.005 \sim 5 \mathrm{sec}($ Automatic adjustment $)$ \\
\hline
\end{tabular}

Replacing the optical entrance to the proposed fiber ball, every 32 second of solar direct and diffuse irradiance can be measured. The aperture angle is set at 32 second which corresponds to the viewing angle of the sun. Outlook of the proposed system for measurement of solar direct and diffuse irradiance is shown in Fig.3 (a). At the top of Fig.3, there is the fiber ball with a number of holes. The holes are optical entrance of the optical guide of optical fibers. The guided lights are input to the MS-720 through attachment at the optical entrance. Illustrative view of the fiber ball is shown in Fig.3 (b) while the configuration of the proposed measuring instrument with fiber ball and MS-720 of radiometer is illustrated in Fig.3 (c). On the other hand, the dimension of the fiber ball radiometer is illustrated in Fig.3 (d). The number of 
holes of the fiber ball is 512 for the hemisphere. One of the problems of the proposed fiber ball is solar direct and diffuse angle pointing accuracy. The difference between sun ephemeris and pointing whole location of the fiber ball would be a problem.

The diameter of the fiber ball is just $5 \mathrm{~cm}$. The hole size is 32 second in diameter which corresponds to $1.1 \mathrm{~mm}$. On the other hand, the diameter of the fiber is 20 micro-meter. Loss of the optical fiber is negligible because the length of the fiber is very short between the tip of the hole of the fiber ball and optical entrance of the MS-720 as shown in Fig.3 (c). The guided light is input to the grating of beam splitter and then the splitter light is guided to the two dimensional CCD array with 20000 of elements.

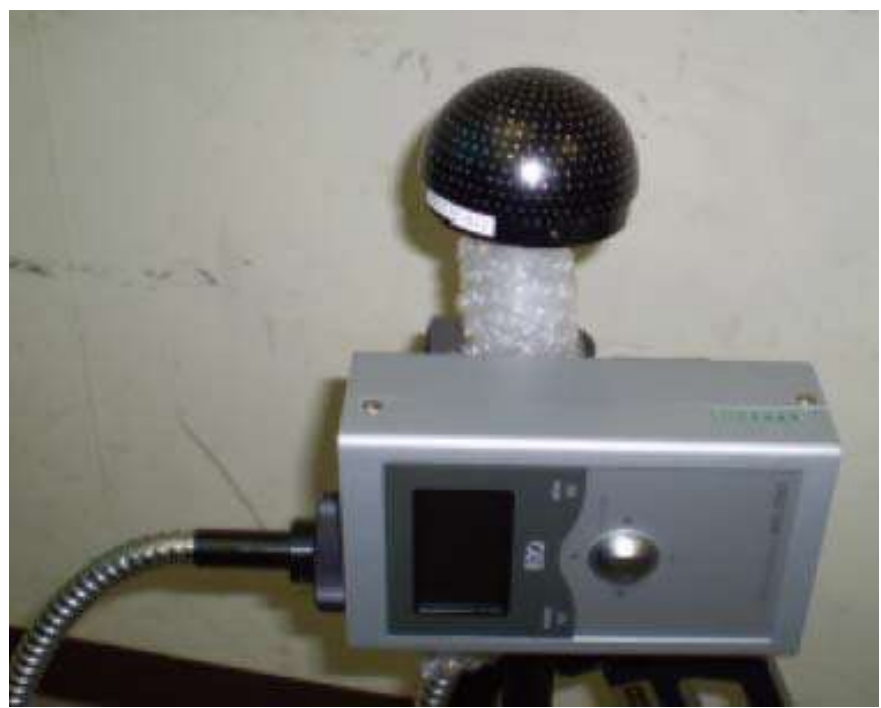

(a) Outlook

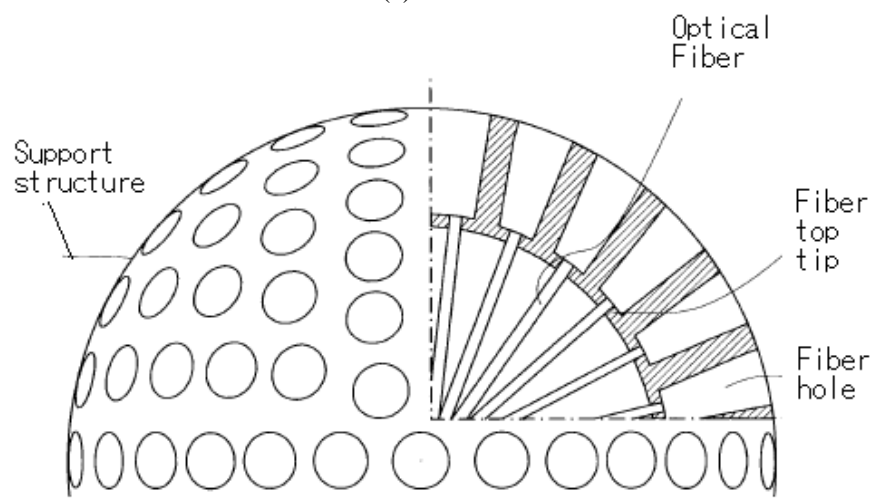

(b) Fiber ball

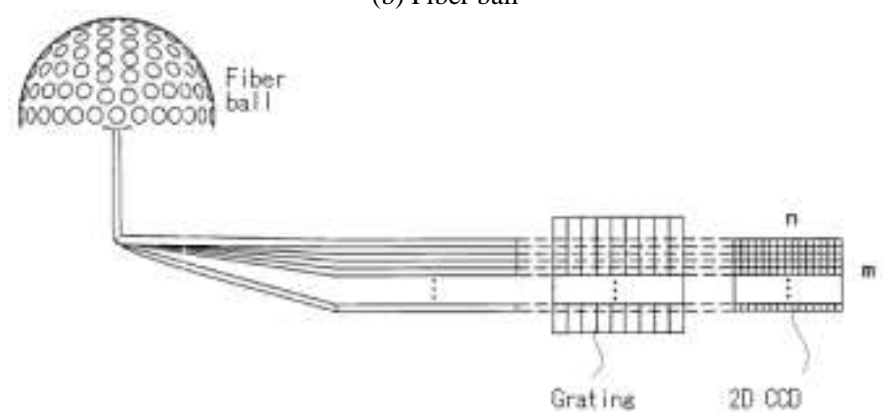

(c) Configuration of the proposed measuring instrument with fiber ball and MS-720 of radiometer

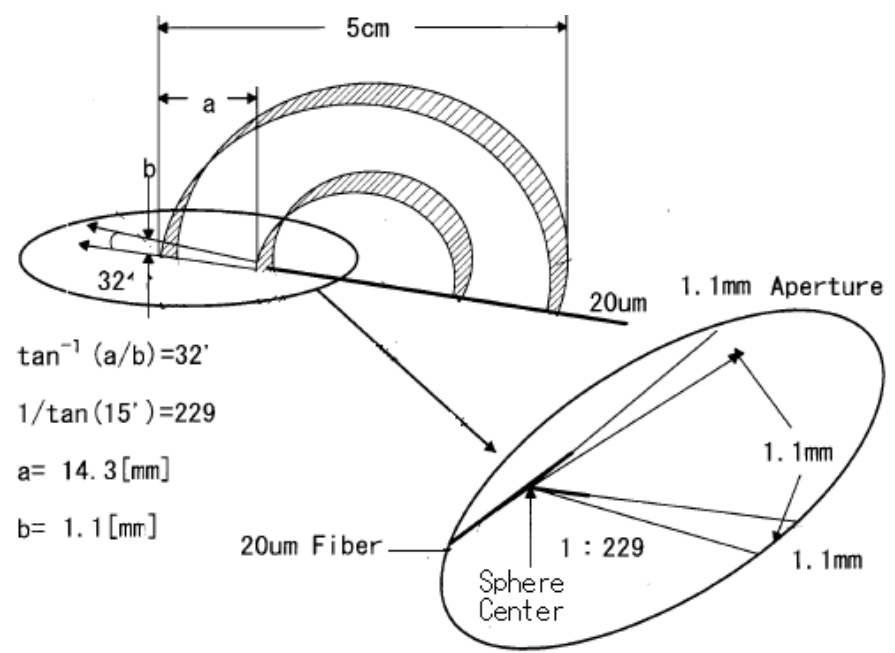

(d) Dimension of the fiber ball radiometer

Fig. 3. (a) Optical Fiber guided sky-radiometer, (b) fiber ball and (c) configuration of instrument. (d) Dimension of the fiber ball radiometer

\section{Radiative Transfer Equation}

Measured solar direct irradiance $F$ on the ground is expressed in equation (1)

$F=F_{0} e^{-m_{0} \tau_{i}}$

where $F_{0}$ denotes extraterrestrial solar flux, $m_{0}$ denotes airmass which can be represented as $1 / \cos (\theta)$ where $\Theta$ denotes solar zenith angle, and $\tau_{t}$ denotes atmospheric optical depth which can be expressed in equation (2)

$$
\tau_{t}=\tau_{a}+\tau_{m}=\tau_{a s}+\tau_{a a}+\tau_{m s}+\tau_{m a}
$$

where the first suffix $t, a$ and $m$ denotes total atmosphere, aerosols and molecules, respectively while the second suffix $a$ and $s$ denotes absorption and scattering, respectively. $F$ can be measured on the ground while $F_{0}$ is well modeled by many researchers. On the other hand, $m_{0}$ can be well determined which results in estimation of atmospheric optical depth. Atmospheric optical depth due to aerosol and molecule has to be estimated together with their absorption and scattering components.

Meanwhile, measured solar diffuse irradiance on the ground can be expressed in equation (3).

$$
E\left(\theta_{0}, \varphi\right)=E(\vartheta)=F m_{0} \Delta \Omega\left\{\omega \tau_{t} P(\vartheta)+q(\vartheta)\right\}
$$

where $\varphi$ denotes the angle between solar azimuth and observation azimuth directions while $\vartheta$ denotes azimuth and elevation angles. There is the following relation between both angles,

$$
\cos (\vartheta)=\cos ^{2} \theta_{0}+\sin ^{2} \theta_{0} \cos \varphi
$$

$\Delta \Omega$ denotes solid angle of the solar diffuse measuring instrument while $\omega$ denotes single scattering albedo which can be represented as follows,

$$
\omega=\left(\tau_{a s}+\tau_{m s}\right) / \tau_{t_{k}}
$$

$P(\vartheta)$ and $q(\vartheta)$ denotes scattering phase function and multiple scattering component, respectively. $P(\vartheta)$ is expressed as follows, 


$$
P(\vartheta)=\left\{\tau_{m s} P_{m}(\vartheta)+\tau_{a s} P_{a}(\vartheta)\right\} /\left(\tau_{m s}+\tau_{a s}\right)
$$

Because of the observation wavelength and molecule radius has the following relation,

$$
\frac{\pi r_{a}}{\lambda}<0.4
$$

molecule component of scattering can be expressed based on the Rayleigh scattering theory. Molecule component of scattering phase function $P_{m}(\vartheta)$ can be expressed as follows,

$$
P_{m}(\vartheta)=\left(\frac{3}{4}\right)\left(1+\cos ^{2} \vartheta\right)
$$

Molecule scattering component of the atmospheric optical depth is represented as follows,

$$
\left\{0.008569 \lambda^{-4}\left(1+0.0113 \lambda^{-2}+0.00013 \lambda^{-4}\right)\right\}\left(\frac{p}{p_{0}}\right)\left(\frac{T_{0}}{T}\right)
$$

where $\lambda$ denotes observation wavelength while $p$ and $p_{0}$ denotes atmospheric pressure on the ground, standard atmospheric pressure $(1013.25 \mathrm{hPa})$, respectively. On the other hand, $T_{0}$ and $T$ denotes standard air-temperature on the ground $(288.15 \mathrm{~K})$ and air-temperature on the ground, respectively.

Meanwhile, observation wavelength and aerosol particle size has the following relation,

$$
0.4<\frac{\pi r_{a}}{\lambda}<3
$$

Aerosol scattering is expressed based on the Mie scattering theory.

Aerosol scattering intensity is expressed as equation (11).

$$
\beta_{a}(\vartheta)=\frac{r^{2}}{2 \pi} \int_{r_{\min }}^{r_{\max }}\left\{i_{1}(\vartheta, x, \tilde{m})+i_{2}(\vartheta, x, \widetilde{m})\right\} n(r) d r
$$

where i1, i2 denotes Mie scattering intensity function as the function of $x$ of size parameter, $\vartheta$, and $\widetilde{m}$ of aerosol refractive index. On the other hand, $n(r)$ denotes the number of aerosol particles of which the radius is $r$ and is called as number of aerosol particle size distribution in unit of $1 / \mathrm{cm}^{2} / \mu$ $\mathrm{m}$.

$$
\mathrm{n}(\mathrm{r})=\mathrm{dN}(\mathrm{r}) / \mathrm{dr}
$$

The size parameter can be represented as follows,

$$
\mathrm{x}=\left(\frac{2 \pi}{\lambda}\right) r
$$

On the other hand, aerosol optical depth is represented as follows,

$$
\tau_{a}=\int_{r_{\min }}^{r_{\max }} \pi r^{2} Q_{\text {ext }}(x, \widetilde{m}) n(r) d r
$$

where $\mathrm{Q}$ is called as Extinction Efficiency Factor. Sometime, the following volume scattering size distribution is used.

$$
\mathrm{v}(\mathrm{r})=\frac{v d}{d \ln r}
$$

There is the well-known relation between the number and volume of size distributions as follows,

$$
\mathrm{v}(\mathrm{r})=\frac{4}{3} \pi r^{4} n(r)
$$

Junge proposed the following size distribution function with Junge parameter $\gamma$,

$$
\mathrm{Cr}^{-\gamma}=\frac{d n}{d \ln r}
$$

In this paper, the Junge function of size distribution is used because of its simplicity with only one Junge parameter.

Let integral kernel functions be

$$
\begin{aligned}
K_{\text {ext }}(x, \widetilde{m}) & =\left(\frac{3}{4}\right) \frac{Q_{\text {ext }}(x, \tilde{m})}{x} \\
\mathrm{~K}(\vartheta, \mathrm{x}, \widetilde{m}) & =\frac{3}{2} \frac{i_{1}(\vartheta, x, \widetilde{m})+i_{2}(\vartheta, x, \widetilde{m})}{x^{3}}
\end{aligned}
$$

Then

$$
\begin{aligned}
& \beta_{a}(\vartheta)=\frac{2 \pi}{\lambda} \int_{r_{\min }}^{r_{\max }} K(\vartheta, x, \tilde{m}) v(r) d \ln r \\
& \tau_{a}=\frac{2 \pi}{\lambda} \int_{r_{\min }}^{r_{\max }} K_{\text {ext }}(x, \tilde{m}) v(r) d \ln r \\
& P_{a}(\vartheta)=\beta_{a}(\vartheta) / \omega_{a} \tau_{a}
\end{aligned}
$$

Solar diffuse irradiance taking into account the multiple scattering in the atmosphere measured on the ground can be represented as follows,

$$
\begin{aligned}
& \mathrm{L}(\vartheta)=F_{0} m_{0} e^{-m \tau_{t}}\left\{\left(\tau_{m s}+\tau_{M S}\right) P_{m}(\vartheta)+\tau_{a s} P_{a}(\vartheta)+\right. \\
& \left.\tau_{A} P_{m}\left(0^{\circ}\right)\right\}
\end{aligned}
$$

where $\left(\tau_{m s} P_{m}(\vartheta)\right)$ implies Rayleigh scattering component while $\left(\tau_{M S}\right) P_{m}(\vartheta)$ implies multiple scattering component in the atmosphere. On the other hand, $\tau_{a s} P_{a}(\vartheta)$ implies aerosol scattering component while $\tau_{A} P_{m}\left(0^{\circ}\right)$ implies multiple scattering component in the atmosphere after the reflection on the ground. Solar diffuse flux can be expressed as L( $\vartheta)$ multiplied by observation solid angle $\Delta \Omega$. Meanwhile, $\tau_{M S}$ and $\tau_{A}$ are expressed empirically as follows,

$$
\begin{aligned}
& \tau_{M S}=0.02 \tau_{S S}+1.2 \tau_{S S}^{2} \mu_{0}^{\frac{-1}{4}} \\
& \tau_{A}=\frac{A \tau_{2}}{1-A \tau_{3}}
\end{aligned}
$$

where

$$
\begin{gathered}
\tau_{S S}=\tau_{m s}+\tau_{s a} \\
\mu_{0}=\cos \left(\theta_{0}\right) \\
\tau_{2}=1.34 \tau_{S S} \mu_{0}\left\{1+0.22\left(\frac{\tau_{S S}}{\mu_{0}}\right)^{2}\right\} \\
\tau_{3}=0.9 \tau_{S}-0.92 \tau_{S S}^{2}+0.54 \tau_{S S}^{3}
\end{gathered}
$$

Therefore, the contribution of multiple scattering in the atmosphere is expressed as follows,

$$
\mathrm{q}(\vartheta)=\tau_{M S} P_{m}(\vartheta)+\tau_{A} P_{m}\left(0^{\circ}\right)
$$

\section{Actual Radiative Transfer Equation Solving}

The following much stable parameter is introduced,

$$
R(\vartheta)=\frac{E(\vartheta)}{F m_{0} \Delta \Omega}=\omega \tau_{t} P(\vartheta)+q(\vartheta)=\beta(\vartheta)+q(\vartheta)
$$

Instead of $E(\vartheta), R(\vartheta)$ does not have large influence due to calibration error of the measuring instrument for solar direct and diffuse irradiance. $\omega \tau_{t} P(\vartheta)$ is replaced to $\beta(\vartheta)$. It is called single scattering intensity. Widely used aerosol parameter estimation method and software code is called Skyrad.Pack developed by Teruyuki Nakajima [11]. In the Skyrad.Pack ver.4.2, iteration method is used as follows,

$$
\beta_{a}^{(1)}(\vartheta)=R_{\text {mean }}(\vartheta)
$$




$$
\beta_{a}^{(n+1)}(\vartheta)=R_{\text {mean }}(\vartheta) \beta_{a}^{(n)}(\vartheta) /_{R^{(n)}}(\vartheta)
$$

where (n) denotes the iteration number while $R_{\text {mean }}(\vartheta)$ denotes the measured solar diffuse irradiance. This method is appropriate in the sense of optimization of single scattering albedo and flux, as well as contribution factor of the multiple scattering component. In order to estimated single scattering flux, we have to know aerosol refractive index and size distribution. Therefore, inverse problem solving method is needed for this. The proposed method uses Moore-Penrose generalized inverse matrix method. Volume vector $v$ (r dimension) of unknown size distribution $v^{(n)}(r)$ is assumed to be the matrix $g$ which consists of a measured aerosol scattering flux $\beta_{a}^{(n)}(\vartheta)$ and aerosol optical depth $\tau_{a}^{(n-1)}$. Then,

$$
g=G v+\varepsilon
$$

where $G$ denotes a linear multiple term matrix. Thus, the size distribution can be determined as follows,

$$
v=\left(G^{T} G+\eta H\right)^{-1} A^{T} g
$$

where $\mathrm{H}$ denotes a smoothing matrix while $\eta$ denotes Lagrange multiplier. Thus, aerosol parameters can be estimated with the measured solar direct and diffuse irradiance.

\section{EXPERIMENTS}

\section{A. Preliminary Results}

POM-01 has self-calibration function. Using the function, calibration data is acquired routinely. Calibration coefficient trend can be divided into three periods, March 2003 to July 2004, July 2004 to October 2008, and October to now. Calibration coefficient trend is shown in Fig.4. As shown in Fig.4, the calibration coefficients are relatively stable since October 2008. Therefore, a sensitivity analysis of the solar direct and diffuse pointing angle error on the aerosol parameter estimation is made for the period.

Fine weather condition of sky-radiometer data which is measured at 11:08 in the morning on May 252009 in the third period is selected due to the fact that calibration coefficients in the third period is relatively stable.

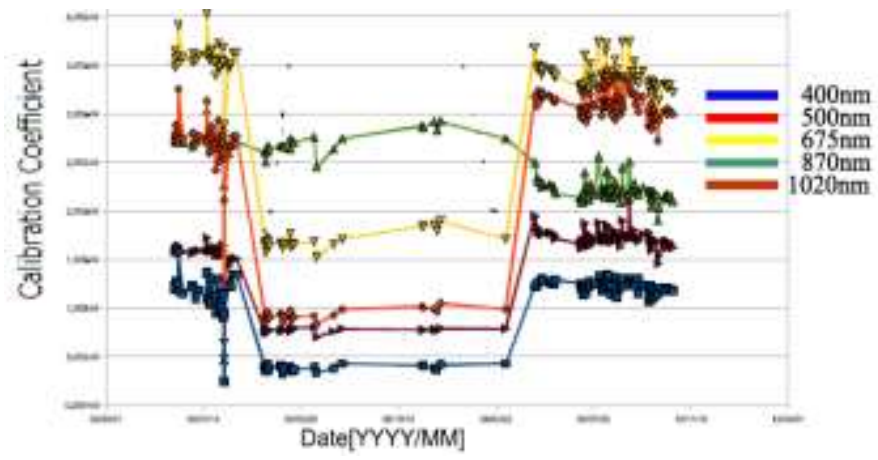

Fig. 4. Calibration coefficient trend of POM-01

\section{B. Experimental Results}

Using the modified skyrad.pack ver.4.2 described above, aerosol parameters, Real and Imaginary parts of aerosol refractive index and size distribution (Junge parameter) are estimated with the measured solar direct and diffuse irradiance which are measured with POM-01 on May 25 2009. Some of the errors are added on the solar direct angle and solar diffuse angle, respectively. Thus sensitivities of the pointing angle error on the estimated aerosol parameters are clarified.

Fig.5 (a) shows the solar direct pointing angle error on the estimated real part of refractive index while Fig.5 (b) shows that for imaginary part of refractive index, respectively. On the other hand, that for aerosol size distribution of Junge parameter is shown in Fig.5 (c). The estimation error is evaluated with Root Mean Square Error: RMSE and percent error. As shown in Fig.5, it is easily found that RMSE increases in accordance with increasing of solar direct pointing angle error. Also, it is found that RMSE increases in accordance with decreasing of wavelength.

On the other hand, Fig.6 shows the solar diffuse pointing angle error on the estimated real and imaginary parts of refractive index as well as Junge parameter. As shown in Fig.6, it is easily found that RMSE increases in accordance with increasing of solar diffuse pointing angle error. Also, it is found that RMSE increases in accordance with decreasing of wavelength. RMSE of estimation error for real part of refractive index is much greater than that for imaginary part of refractive index obviously.

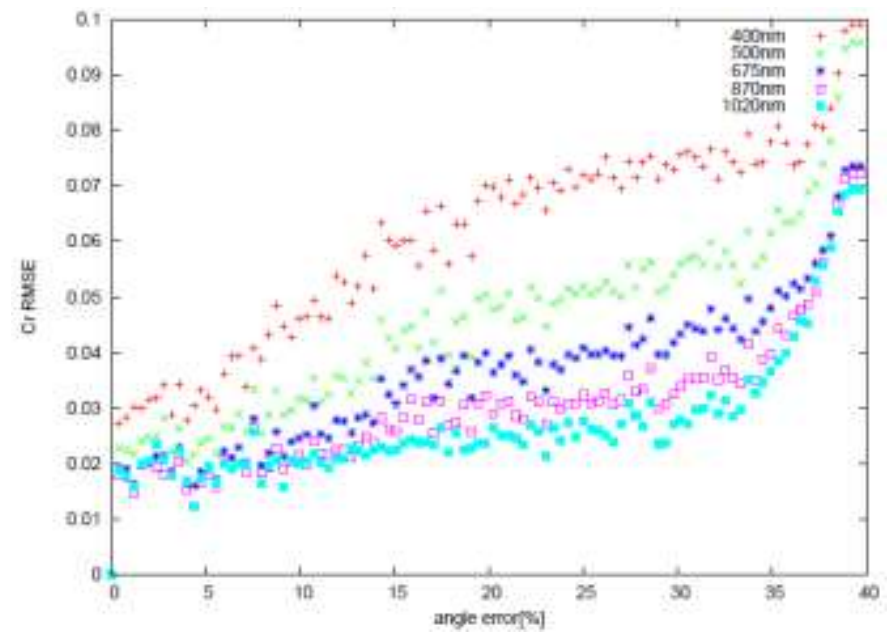

(a) Real part

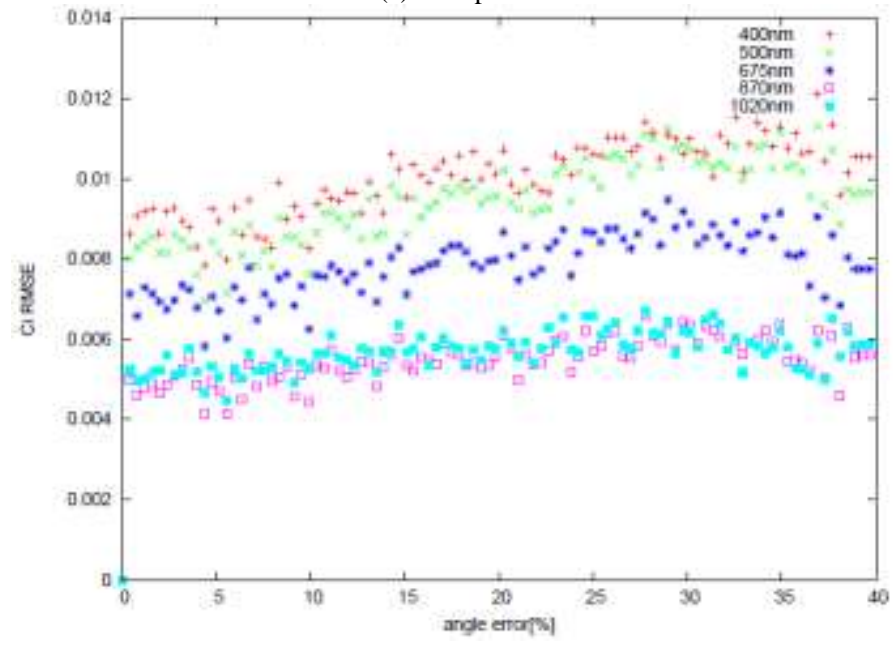

(b) Imaginary part 


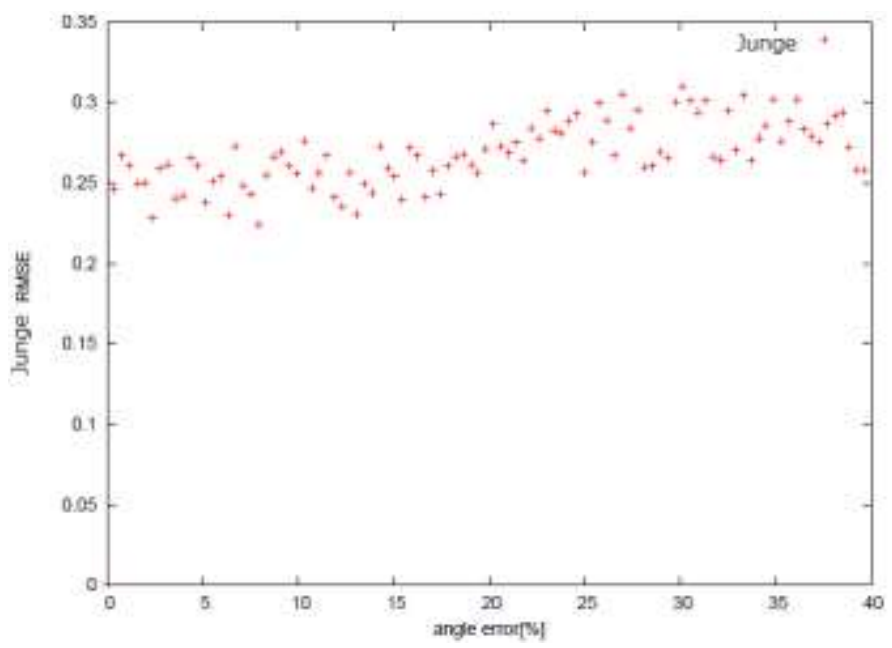

(c) Junge parameter

Fig. 5. RMSE of the aerosol parameter estimation caused by solar direct pointing angle errors

Also, solar diffuse pointing angle error dependency on real part of refractive index is much smooth in comparison to that on imaginary part of refractive index. In other word, the estimated imaginary part of refractive index is much diverse than the estimated real part of refractive index.

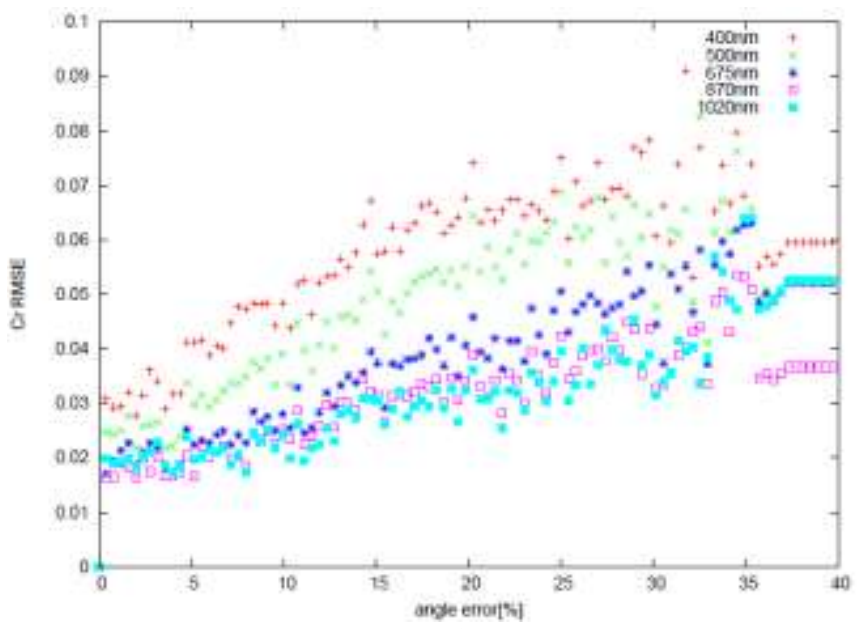

(a) Real part

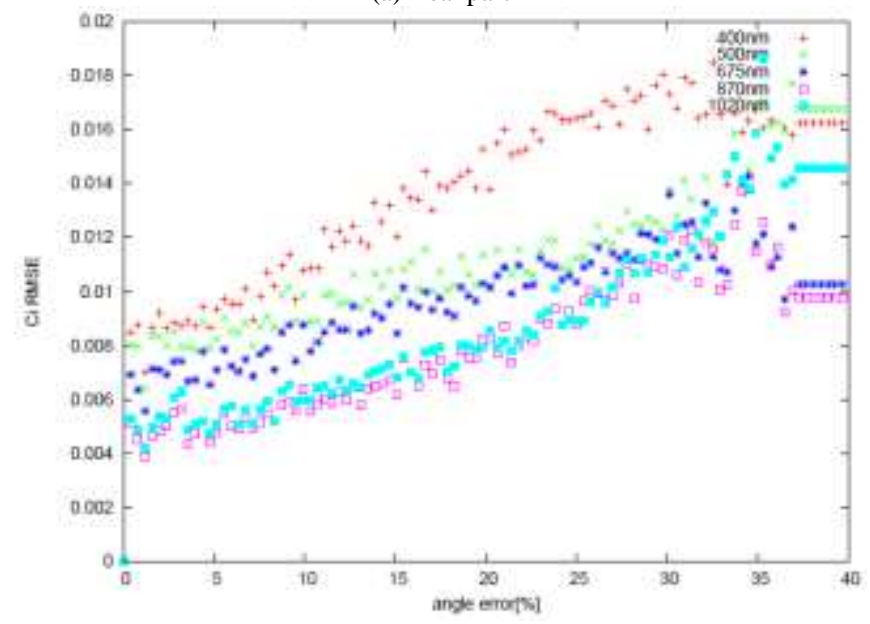

(b) Imaginary part

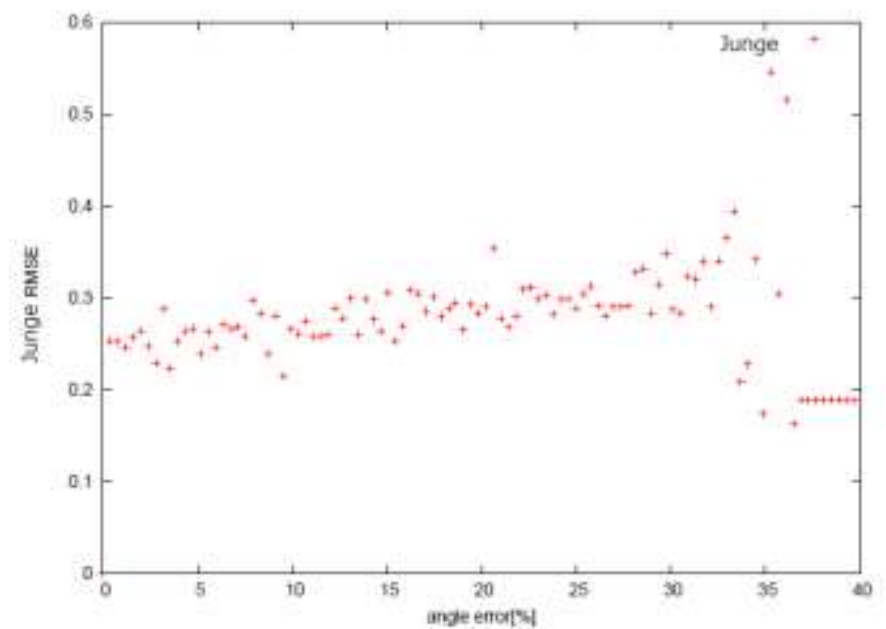

(c) Junge parameter

Fig. 6. RMSE of the aerosol parameter estimation caused by solar diffuse pointing angle errors

This is because of the actual real part of refractive index is much greater than that of imaginary part of refractive index. Furthermore, it is found that RMSE of Junge parameter increases with increasing of solar direct pointing error as shown in Fig.6.

\section{CONCLUSION}

Estimation method of aerosol parameter by means of solar direct and diffuse irradiance measurements with the proposed instrument of fiber-ball radiometer without sun tracking mechanics is proposed. Sky-radiometer and aureole-meter is well known instrument which allows measurements of solar direct and diffuse irradiance for estimation of aerosol parameter.

The proposed fiber-ball radiometer also allows solar direct and diffuse irradiance measurements and is comparatively light as well as is composed without any mechanics so that it is portable and is enable to bring anywhere you want including test sites for field campaigns. Meanwhile, it is not always that the fiber-ball instrument points to the sun due to the error of the sun ephemeris calculations as well as sun track do not match to the actual one.

Influence due to pointing error on aerosol parameter estimation error is clarified. Possible maximum pointing error may cause some error on aerosol parameter estimation. Experimental results show that $0.43 \%, 42.23 \%, 2.12 \%$ root mean square errors are suspected for real and imaginary part of refractive index and Junge parameter as of 1.747, 0.0056 and 3.0 of typical case of atmosphere.

\section{ACKNOWLEDGEMENTS}

Author would like to thank Mr. Yu Odeishi of former student of Saga University for his effort for conducting the experiments.

\section{REFERENCES}

[1] Shaw, G.E., Error analysis of multi-wavelength sunphotometry. Pure Appl. Geophys., 114, 1, 1976.

[2] Hoppel, W. A., J. W. Fitzgerald, G. M. Frick, R. E. Larson, and E. J. Mack, Aerosol size distributions and optical properties found in the 
marine boundary layer over the Atlantic Ocean, J. Geophys. Res., 95, 3659-3686, 1990.

[3] Holben, B. N., et al., AERONET- A federated instrument network and data achieve for aerosol characterization, Remote Sens., 12, 1147-1163, 1991.

[4] Holben, B.N., and Coauthors, AERONET-A federated instrument network and data archive for aerosol characterization. Remote Sens. Environ., 66, 1-16. 1998.

[5] Aoki, K., T. Takamura, and T. Nakajima, Aerosol optical properties measured by SKYNET sky radiometer validation network. Proc. of the 2nd EarthCARE Workshop, 133-134, 2005.

[6] Redemann, R. P. Turco, K. N. Liou, P. B. Russell, R. W. Bergstrom, B. Schmid, J. M. Livingston, P. V. Hobbs, W. S. Hartley, S. Ismail, R. A Ferrare, E. V. Browell, Retrieving the vertical structure of the effective aerosol complex index of refraction from a combination of aerosol in situ and remote sensing measurements during TARFOX, J. Geophys. Res., 105, D8, 9949-9970, 2000.

[7] M.L.Clapp, and R.E.Miller, Complex Refractive Indices of Crystalline Hydrazine from Aerosol Extinction Spectra, Icarus, 23, 2, 396-403(8), 1996.

[8] R. Eiden, Determination of the complex index of refraction of spherical aerosol particles, Appl. Opt. 10, 749-757, 1971.

[9] G. E. Thomas, S. F. Bass, R. G. Grainger, and A. Lambert, Retrieval of aerosol refractive index from extinction spectra with a damped harmonic-oscillator band model, Appl. Opt. 44, 1332-1341, 2005.

[10] Kohei Arai, Aerosol refractive index retrievals with atmospheric polarization measuring data, Proceedings of the SPIE, 7461-06, 1-9, 2009

[11] Teruyuki Nakajima, et al., Use of sky brightness measurements from ground for remote sensing of particulate polydispersions, Applied Optics, Vol.35 No..15 pp.2672-2686 May 1996.

[12] Teruyuki Nakajima, et al., Retrieval of the optical properties of aerosols from aureole and extinction data, Applied Optics, Vol.22 No..19 pp.2951-2959 October 1983.

[13] M. A. Box and A. Deepak, An Approximation to Multiple Scattering in the Earth's Atmo-sphere:Almucanter Radiance Formulation, J. Atmos. Sci. Vol38 pp.1037-1048 1981.

[14] Mitsugu Toriumi, Hideaki Takenaka, Tadashi Kato, Toshikazu Hasegawa, Takashi Nakajima, Tamio Takamura and Teruyuki Nakajima: Estimation of Aerosol Optical Thickness by PAR Radiometer, Journal of The Remote Sensing Society of Japan, 30, 2, pp.81-89, 2010 .

[15] Tsutomu Takashima, Kazuhiko Masuda, Kohei Arai, Satoshi Tsuchida, Observation of Optical Property of the Atmosphere in Particular Aerosols at Deserted Areas In USA Using Sun-photometer and Polarization Spectrometer, Journal of Remote Sensing Society of Japan, Vol.20, No.3, pp.47-60, (2000).

[16] Kohei Arai, Influence of Non-Spherical Sea Salt Aerosol Particles Containing Bubbles on the Top of the Atmosphere Radiance, Journal of Remote Sensing Society of Japan, Vol.20, No.5, pp.32-39, (2001).

[17] Kohei Arai, Tatsuya Kawaguchi, Adjucency Effect of Layered Clouds taking Into Account Phase Function of Cloud Particles and MultiLayered Plane Parallel Atmosphere Based on Monte Carlo Method, Journal of Japan Society of Photogrammetry and Remote Sensing, Vol.40, No.6, 2001.

[18] Kohei Arai, Yoko Takamatsu, Influence of Spume Aerosol Particles on the Top of the Atmosphere Radiance, Journal of Remote Sensing Society of Japan, Vol.23, No.4, pp.355-363, 2003.
[19] Kohei Arai, Xing Ming Liang, Estimation of Method for the Top of the Atmosphere Radiance Taking Into Account Polarized Up-welling and Down-welling Radiance, Journal of Japan Society of Photogrammetry and Remote Sensing, 44,3, 4-12,(2005)

[20] K.Arai, Monte Carlo simulation of polarized atmospheric irradiance for determination of refractive index of aerosols, International Journal of Research and Review on Computer Science, 3, 4, 1744-1748, 2012.

[21] K.Arai, Monte Carlo ray tracing based sensitivity analysis of the atmospheric and oceanic parameters on the top of the atmosphere radiance, International Journal of Advanced Computer Science and Applications, 3, 12, 7-13, 2012.

[22] K.Arai, Monte Carlo ray tracing based sensitivity analysis of the atmospheric and oceanic parameters on the top of the atmosphere radiance, International Journal of Advanced Computer Science and Applications, 3, 12, 7-13, 2012.

[23] Kohei Arai, Method for estimation of aerosol parameters based on ground based atmospheric polarization irradiance measurements, International Journal of Advanced Computer Science and Applications, 4, 2, 226-233, 2013.

[24] Kohei Arai, Sensitivity analysis and validation of refractive index estimation method with ground based atmospheric polarized radiance measurement data, International Journal of Advanced Computer Science and Applications, 4, 3, 1-6, 2013.

[25] Kohei Arai, Sensitivity analysis for aerosol refractive index and size distribution estimation methods based on polarized atmospheric irradiance measurements, International Journal of Advanced Research in Artificial Intelligence, 3, 1, 16-23, 2014.

[26] K.Arai, Vicarious calibration data screening method based on variance of surface reflectance and atmospheric optical depth together with cross calibration, International Journal of Advanced Research on Artificial Intelligence, 4, 11, 1-8, 2015.

[27] K.Arai, Kenta Azuma, Method for surface reflectance estimation with MODIS by means of bi-section between MODIS and estimated radiance as well as atmospheric correction with sky-radiometer, International Journal of Advanced Research on Artificial Intelligence, 4, 11, 8-15, 2015.

\section{AUTHORS PROFILE}

Kohei Arai, He received BS, MS and PhD degrees in 1972, 1974 and 1982, respectively. He was with The Institute for Industrial Science and Technology of the University of Tokyo from April 1974 to December 1978 and also was with National Space Development Agency of Japan from January, 1979 to March, 1990. During from 1985 to 1987, he was with Canada Centre for Remote Sensing as a Post-Doctoral Fellow of National Science and Engineering Research Council of Canada. He moved to Saga University as a Professor in Department of Information Science on April 1990 He was a counselor for the Aeronautics and Space related to the Technology Committee of the Ministry of Science and Technology during from 1998 to 2000. He was a councilor of Saga University for 2002 and 2003. He also was an executive councilor for the Remote Sensing Society of Japan for 2003 to 2005. He is an Adjunct Professor of University of Arizona, USA since 1998. $\mathrm{He}$ also is Vice Chairman of the Commission-A of ICSU/COSPAR since 2008. He received Science and Engineering Award of the year 2014 from the minister of the ministry of Science Education of Japan and also received the Bset Paper Award of the year 2012 of IJACSA from Science and Information Organization: SAI. In 2016, he also received Vikram Sarabhai Medal of ICSU/COSPAR and also received 20 awards. He wrote 34 books and published 520 journal papers. He is Editor-in-Chief of International Journal of Advanced Computer Science and Applications as well as International Journal of Intelligent Systsems and Applications. http://teagis.ip.is.sagau.ac.jp/ 